\title{
Three-dimensional quantification of tree architecture from mobile laser scanning and geometry analysis
}

\author{
Yonten Dorji ${ }^{1,6} \cdot$ Bernhard Schuldt $^{2} \cdot$ Liane Neudam $^{1} \cdot$ Rinzin Dorji ${ }^{1} \cdot$ Kali Middleby $^{3} \cdot$ Emilie Isasa $^{2} \cdot$ Klaus Körber $^{4}$. \\ Christian Ammer ${ }^{1} \cdot$ Peter Annighöfer $^{5} \cdot$ Dominik Seidel $^{1}$
}

Received: 13 November 2020 / Accepted: 25 March 2021 / Published online: 12 April 2021

(c) The Author(s) 2021

\begin{abstract}
Key message Mobile laser scanning and geometrical analysis revealed relationships between tree geometry and seed dispersal mechanism, latitude of origin, as well as growth.

Abstract The structure and dynamics of a forest are defined by the architecture and growth patterns of its individual trees. In turn, tree architecture and growth result from the interplay between the genetic building plans and environmental factors. We set out to investigate whether (1) latitudinal adaptations of the crown shape occur due to characteristic solar elevation angles at a species' origin, (2) architectural differences in trees are related to seed dispersal strategies, and (3) tree architecture relates to tree growth performance. We used mobile laser scanning (MLS) to scan 473 trees and generated three-dimensional data of each tree. Tree architectural complexity was then characterized by fractal analysis using the box-dimension approach along with a topological measure of the top heaviness of a tree. The tree species studied originated from various latitudinal ranges, but were grown in the same environmental settings in the arboretum. We found that trees originating from higher latitudes had significantly less top-heavy geometries than those from lower latitudes. Therefore, to a certain degree, the crown shape of tree species seems to be determined by their original habitat. We also found that tree species with wind-dispersed seeds had a higher structural complexity than those with animal-dispersed seeds $(p<0.001)$. Furthermore, tree architectural complexity was positively related to the growth performance of the trees $(p<0.001)$. We conclude that the use of 3D data from MLS in combination with geometrical analysis, including fractal analysis, is a promising tool to investigate tree architecture.
\end{abstract}

Keywords Tree architecture $\cdot$ LiDAR $\cdot$ Fractal analysis $\cdot$ Seed dispersal strategy $\cdot$ Latitude $\cdot$ Tree growth

Communicated by Ishii.

Yonten Dorji

Yonten.dorji@uni-goettingen.de

1 Silviculture and Forest Ecology of the Temperate Zones, Faculty of Forest Sciences, Georg-August-Universität Göttingen, Büsgenweg 1, 37077 Göttingen, Germany

2 Ecophysiology and Vegetation Ecology, Julius-Maximilian University of Würzburg, Julius-von-Sachs-Platz 3, 97082 Würzburg, Germany

3 College of Science and Engineering, James Cook University, Cairns, QLD 4870, Australia

4 Institute for Commercial and Recreational Horticulture, Bavarian State Institute for Viticulture and Horticulture, An der Steige 15, 97209 Veitshochheim, Germany

5 Forest and Agroforest Systems, Technical University of Munich, Hans-Carl-v.-Carlowitz-Platz 2, 85354 Freising, Germany

6 College of Natural Resources, Royal University of Bhutan, Punakha 1264, Bhutan

\section{Introduction}

The science of tree structure and form dates back to Leonardo da Vinci, who investigated the cross-sectional area of branches and found it to be maintained across branching orders (Richter 1970). Later, the 'concept of tree architecture' and its effect on the ecology and adaptive strategy of trees were comprehensively presented by Hallé and Oldeman (1970). Furthermore, to describe tree growth and form, 23 different tree architectural models or 'genetic blueprints' were developed, which were considered universal descriptions of tree growth for various species (Hallé et al. 1978). The structure and dynamics of a forest stand are ultimately related to the architecture of the individual trees (West et al. 2009; Price et al. 2012; Seidel et al. 2019a). Therefore, the study of tree structure and form is highly relevant to diverse research fields, such as phylogeny and taxonomy, ecosystem modeling, tree physiology, and crucial for remote sensing of 
canopy landscapes, tree wind damage studies, carbon stock calculation for climate change mitigation schemes, as well as metabolic scaling theory (Malhi et al. 2018).

Tree architecture ranges from slender, pole-like forms to large, sprawling, multilayered canopies (Beech et al. 2017), and there is likely no identically shaped pair of trees amongst all, even within a species (Seidel et al. 2019b). It is already known that tree architecture is not entirely random (Valladares and Niinemets 2007), and that it is determined by the dynamic response of tree growth to its abiotic and biotic environment, in the context of its genetic code (Hallé et al. 1978; Scorza et al. 2002; Busov et al. 2008; Burkardt et al. 2020). Tree shape has been shown to be influenced by environmental factors such as wind (Noguchi 1979; Watt et al. 2005; De Langre 2008), water availability (Archibald and Bond 2003), light availability (Kuuluvainen 1992; Niinemets and Kull 1995), terrain slope (Barij et al. 2007), and competition (Bayer et al. 2013; Juchheim et al. 2017). This adaptive geometry of trees (Horn 1971; Borchert and Slade 1981) is likely the result of an individual's need to optimize fitness in a given location, which would include the need for structural stability, light interception, and reproductive success (Valladares and Niinemets 2007; Honda and Fisher 1978; Hollender and Dardick 2015). Over time, many studies have observed an effect of genetic predisposition on tree growth and branching patterns (Bradshaw and Stettler 1995; Scotti-Saintagne et al. 2004; Wu and Stettler 1998; Kenis and Keulemans 2007; Segura et al. 2006). Depending on the environmental conditions at the growing site, many trees have a particular form that is distinguishable (Lindh et al. 2018; Malhi et al. 2018).

For trees, branching geometry and the resulting crown shape have a great influence on radiation utilization (Niklas 1986). Several studies showed the major role of crown architecture in the light interception process (Hallé et al. 1978; Iwasa et al. 1985; Guisasola et al. 2015; Forrester et al. 2018; Lindh et al. 2018). Therefore, crown architecture is also decisive for carbon and water fluxes between the trees and the atmosphere (Enquist et al. 2009). Kuuluvainen (1992) observed that depending on the solar angle of the sun determined by the latitude, there are different crown shapes of trees. It was argued that the variation in sun elevation angle in a given location is so systematic that "it seems reasonable to expect that tree architectures show traits that allow them to efficiently utilize light" (Kuuluvainen 1992).

Solar interception is not the only factor determining species fitness. For example, seed dispersal impacts the success of propagation, and is also influenced by tree architecture (Malhi et al. 2018). Although seed dispersal strategies have been studied extensively (Darwin 1859; Schmidt 1918; Hamrick et al. 1993; Wagner et al. 2004; Tiebel et al. 2019), studies on the relationship between seed dispersal strategy and tree architecture are less common (Malhi et al. 2018).
To date, we are aware of no study that has investigated the relationship between tree crown complexity and seed dispersal strategy. This is because tree architecture and structural complexity are difficult to quantify (Su et al. 2020; Guzmán et al. 2020). While Xu et al. (2019) did find a relationship between tree parameters of height-stem diameter relationships and seed dispersal type in a subtropical montane moist forest (with wind-dispersed strategies common in largestatured tree species, and animal mediated dispersal more common in understory species), their study did not consider crown complexity. In addition, individuals were measured in the field, where confounding variables such as competition by neighboring trees could not be controlled.

Until recently, highly labor-intensive and time-consuming methods were used to address tree structure in detail (Bentley et al. 2013) whenever the rather qualitative architectural models of the past did not satisfy the needs of modern science. Approaches to quantitatively assess tree structure and form were based on measures of specific tree features, such as height (e.g., Sterck and Bongers 2001), diameter of the stem (e.g., Gering and May 1995) or crown base height (e.g., Sprinz and Burkhart 1987) among many others. Lately, three-dimensional data from laser scanning approaches (LiDAR) are also used to derive tree characteristics such as tree crown volume (Moorthy et al. 2011), crown surface area (Metz et al. 2013), crown radius (Seidel et al. 2015), or even detailed branching pattern like branch angles, branch lengths and branch volumes (Tao et al. 2015; Disney 2019; Li et al. 2018; Dorji et al. 2019). In fact, LiDAR is revolutionizing the way we look at trees (Gonzalez de Tanago et al. 2018). By allowing changes in tree architecture to be observed, the 3D data of the actual tree form can help to improve our understanding of why trees are shaped a certain way.

Recently, with the new means of 3D characterization of tree structure based on laser scanning, the use of fractal analysis has become possible for further analysis of tree architecture (Seidel 2018). Fractal geometry has been utilized as a tool for analyzing non-linear, fragmented, and irregularly structured objects, such as corals (Martin-Garin et al. 2007), organs (Losa 2012), and plants (Hasting and Sugihara 1993). It was introduced by the mathematician Benoit Mandelbrot in the 1970s to describe the complexity of a broad range of objects based on the degree to which the object can fill the available space (Mandelbrot 1977). In fractal analysis, the box dimension $\left(D_{\mathrm{b}}\right)$ is a measure that can be used to assess the architectural complexity of trees holistically (Seidel et al. 2019a). By observing the change in the number of virtual boxes, one needs to fill the entire space occupied by an object in dependence of the size of the boxes one uses, and the box dimension is quantified in $3 \mathrm{D}$ model space. $D_{\mathrm{b}}$ was shown to be sensitive to characteristics of tree shape as well as the internal structure of the tree crowns (Seidel 2018). It was also shown to be positively related to the growth of 
several temperate and tropical species (Seidel 2018; Seidel et al. 2019b). The approach integrates the whole tree architecture in a single number, the box dimension, which was also successfully related to functional aspects of trees (Seidel et al. 2019b).

In this study, we use $D_{\mathrm{b}}$ with the aim to observe the relationship between seed dispersal strategy and tree architecture, as well as to investigate the effect of the $D_{\mathrm{b}}$ on tree growth. Additionally, we used a topological measure of a tree's top-heaviness, namely the relative height of maximum horizontal crown area (Rel.Hmaxarea), to address Kuuluvainen's theory of tree shapes depending on the latitude of a species home range due to the prevalent solar elevation angles.

We aimed at addressing the question of whether the adaptation of tree species to the solar elevation at their place of origin is still visible in the tree architecture of individuals of the same species at their place of growth. In theory, there is a gradient from wider and flatter or domed tree crowns in the tropics to more vertically shaped and elongated crowns at high latitude (Oker-Blom and Kellomaki 1982; Kuuluvainen 1992). Therefore, from our 3D point cloud data of the trees, we hypothesize that (1) trees originating from different latitudes show crown shapes reflecting adaptations to the condition at their home range latitude, (2) the genetic building plan of a tree is optimized for the seed dispersal strategy which may reflect in the box dimension, and (3) the radial increment of a tree is related to the box dimension of the tree.

\section{Materials and methods}

\section{Study site}

This study was conducted in the Stutel-Arboretum near Würzburg, Bavaria, Germany ( $49^{\circ} 51^{\prime} 49^{\prime \prime}$ N, $9^{\circ} 51^{\prime} 8^{\prime \prime}$ E). It is located at an elevation of $180 \mathrm{~m}$ above sea level at the right bank of the river Main. The climate of the study area is characterized by a mean annual temperature of $9.5^{\circ} \mathrm{C}$ and a mean annual precipitation of $603 \mathrm{~mm}$. It falls under the humid continental climate type as per the Köppen climate classification. However, drought events occur frequently on the site during summer month. The study site is characterized by a sandy anthrosol (according to the world reference base for soil resources) with a $\mathrm{pH}$ value of around 7.3.

The arboretum harbors more than 400 tree species from different origins around the world, with latitudinal midpoints spanning approximately from $25^{\circ}$ to $75^{\circ}$. The trees were first raised in different nurseries in Europe and Asia, and then brought to the arboretum as seedlings (maximum age of 2 years). The trees were then planted and raised in the arboretum since 2010 under the extensive project called
'Klimabäume Stutel' by the Bavarian State Institute for Viticulture and Horticulture (LWG), which aims to assess the suitability of various tree species as future urban trees. The trees are monitored periodically by recording their growth but are maintained without disturbance to their growth form with the exception of some minor pruning in the first year after planting. We investigated 473 trees of 41 genera and 105 species and varieties. The trees were planted in 42 rows with a spacing of at least $3 \times 3 \mathrm{~m}$. The location of the study site is provided in Fig. 1.

In the arboretum, trees were grown in a fashion suitable for the interpretation of tree architectures resulting from their genetic makeup. Specifically, trees shared a common soil, geographical setting (south-west facing aspect and mild slope), and climatic condition, and were grown without interference from neighboring trees, or any major disturbance to their growth form.

\section{Mobile Laser scanning}

A ground-based mobile laser scanning (MLS) system was used (Geoslam ZEB-HORIZON, Geoslam Ltd., UK 2019) to obtain 3D point cloud data for accurate measurement and mapping of the environment. The MLS device has the advantage of being easy to use without preparations on site. It saves the time required to set up a tripod or reference points (as common practice in terrestrial laser scanning) and also provides automatic data registration (coregistration of the different scan perspectives). The maximum range of the ZEB-HORIZON is $100 \mathrm{~m}$ under ideal conditions and about $50 \mathrm{~m}$ in real-life outdoor conditions. It uses a laser with a wavelength of $903 \mathrm{~nm}$ and scans at a rate of 300,000 points per second. The scan range noise is $\pm 30 \mathrm{~mm}$. Based on the SLAM algorithm (Simultaneous Locating and Mapping), the scanner constantly captures the environment while walking around.

\section{Data collection}

The scanning was carried out in February 2020 when the trees were leafless, to ensure free sight on the tree crowns. All 473 trees were scanned carrying the scanner in the hand at around breast height with the arm outstretched while moving at a slow walking pace. In MLS, the selection of the walking path is important for a good tree representation from all sides. We walked in a zig-zag route around the trees and covered two planting rows at a time in each scan by following the direction of the row and finally ending at the exact point where the scan started (up and down the row). We made sure to close the loop every time. By zig-zagging every other tree on the way back, we covered all trees from both sites (see Fig. 2). 


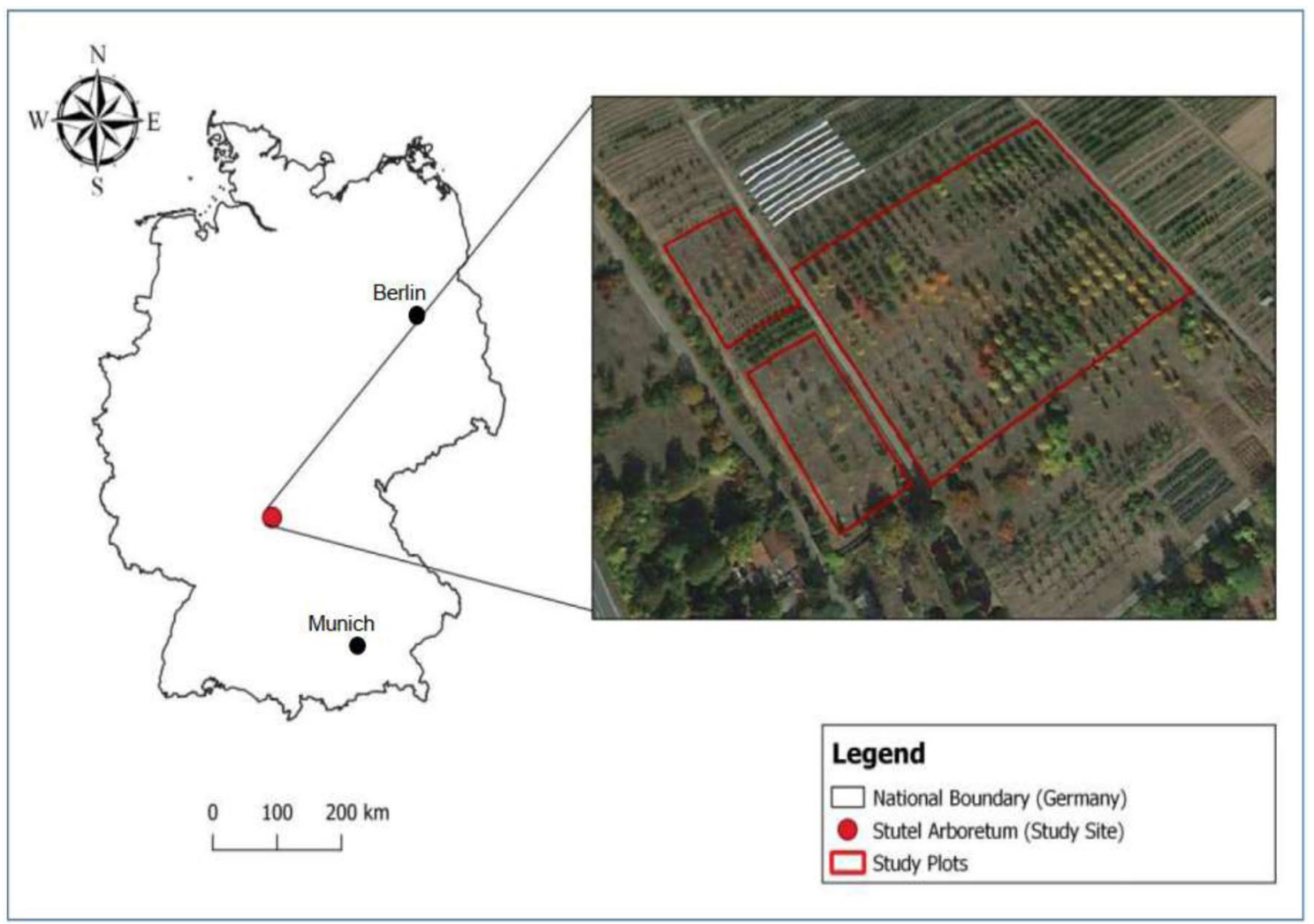

Fig. 1 Map of Germany with the location of the research site at Stutel-arboretum, Würzburg, Germany, and an aerial view of the arboretum (Google Earth 2013) with the three study plots chosen for our scanning campaign

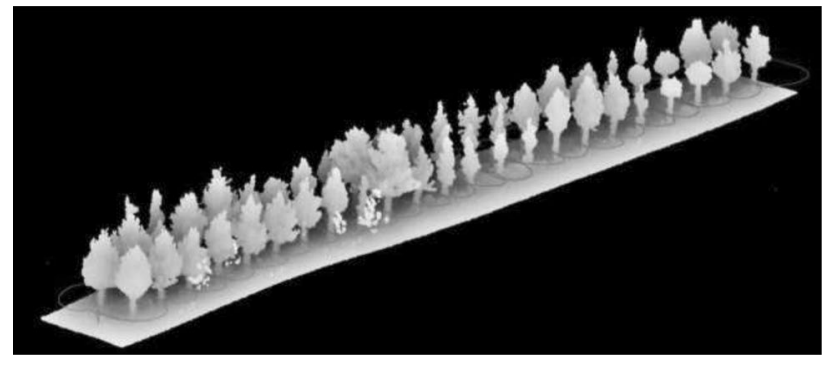

Fig. 2 Exemplary picture of trees of two rows after processing a mobile scan in GeoSlam Hub. The red line indicates the trajectory of the device during scanning with the loop being closed for each scan at the front left (start and end at beginning of row). Two tree rows were always scanned at a time by a zig-zagging walking path trajectory surrounding each tree in the two rows

We obtained records of the periodical circumference measurements for 391 of the individual trees since the time of plantation from the Bavarian State Institute for Viticulture and Horticulture (LWG). Tree circumference was measured using calipers. We calculated the difference between the initial plantation radial measurement and the present radius of the tree individuals as a measure of tree growth and expressed it as annual radial increment.

\section{Species information (origin, latitudinal range, and seed dispersal strategy)}

The secondary data for the places of species origin and latitudinal range were obtained from the database of the European Forest Genetic Resources Program (EUFORGEN 1994) and Van Den Berk Nurseries (Vdberk 2020). To compare the top heaviness (Rel.Hmaxarea, see Chap. 2.8) with the latitudinal range of the species, the mid-point of their maximum and minimum latitudinal distribution was calculated. We are aware that this mid-point latitude is of limited accuracy, since highly detailed geographical information on every species' natural distribution would be needed for an exact mid-point determination. This is, however, unavailable for many species. We used the absolute values of the latitudes to analyze both hemispheres together, since we do not assume an effect on tree architecture based on the hemisphere (average solar elevation angles are the same). This analysis was performed for 431 trees from 83 species, since we could not find exact origins for some of the cultivars.

Information regarding seed dispersal strategy was obtained from the Royal Botanic Gardens Kew Seed Information Database (SID 2020) as well as from additional literature (Howe and Smallwood 1982; Clark et al. 1999; Loewer 
2005; Oyama et al. 2018). Tree species were excluded from analysis if their primary seed dispersal strategy could not be clearly identified from the literature, or if there were insufficient individuals for statistical analysis (i.e., species with water dispersed or unassisted dispersal strategies). For analysis of the relationship between seed dispersal strategy and the tree architectural complexity, we considered tree species for which the major seed dispersal strategy was animal-based or wind-based. Out of the 473 trees measured, 320 were used for analysis of seed dispersal strategy, wherein 130 of these were animal-dispersed and 191 were wind-dispersed.

\section{Scan data post-processing}

The raw data collected by the MLS were processed using the 3D SLAM algorithm in the GeoSLAM Hub 6.0 processing software (Geoslam Ltd. UK) to create a .txt-file for each scan and a trajectory-file containing the 3D trajectory of the walking-path.

Open source CloudCompare software (CloudCompare v2.10.1, https://www.danielgm.net/cc/) was then used for post-processing the point clouds. First, we subsampled each scan point cloud to a $1 \mathrm{~cm}$ resolution (downsampling for homogenous point cloud density). Then, we virtually extracted the point cloud of each tree in subsequent steps. We cut the rows of the trees (Fig. 2) and then we cut each tree from the rows and subsequently cleaned outlier points around the individual trees (Fig. 3).

\section{Statistical analysis}

We used the free statistical software R (Vers.3.4, R Development Core Team) for the statistical analysis (R Core Team 2018). We carried out Welch's $t$ test (assuming unequal variance) to test for significant differences between the mean of the box dimension of tree species of the two seed dispersal strategies. Linear regression analysis was used to investigate the relationship between the Rel.Hmaxarea (top heaviness) and the latitude of origin. Due to missing linearity, the relationship between the box-dimension and tree growth, presented here as annual radial increment, was analyzed using non-linear Generalized Additive Modeling (GAM) techniques. The effective degrees of freedom (EDF) were limited to a maximum of 4 (number of knots $=5$ ), whereas the amount of smoothing was then chosen automatically through generalized cross-validation (Wood 2017). The data family was set to Gaussian type with an identity-link function. The level of significance was $p<0.05$ for all tests.

\section{Fractal analysis with box dimension}

We used an algorithm written in Mathematica (Wolfram Research, Champaign, USA) to determine the structural

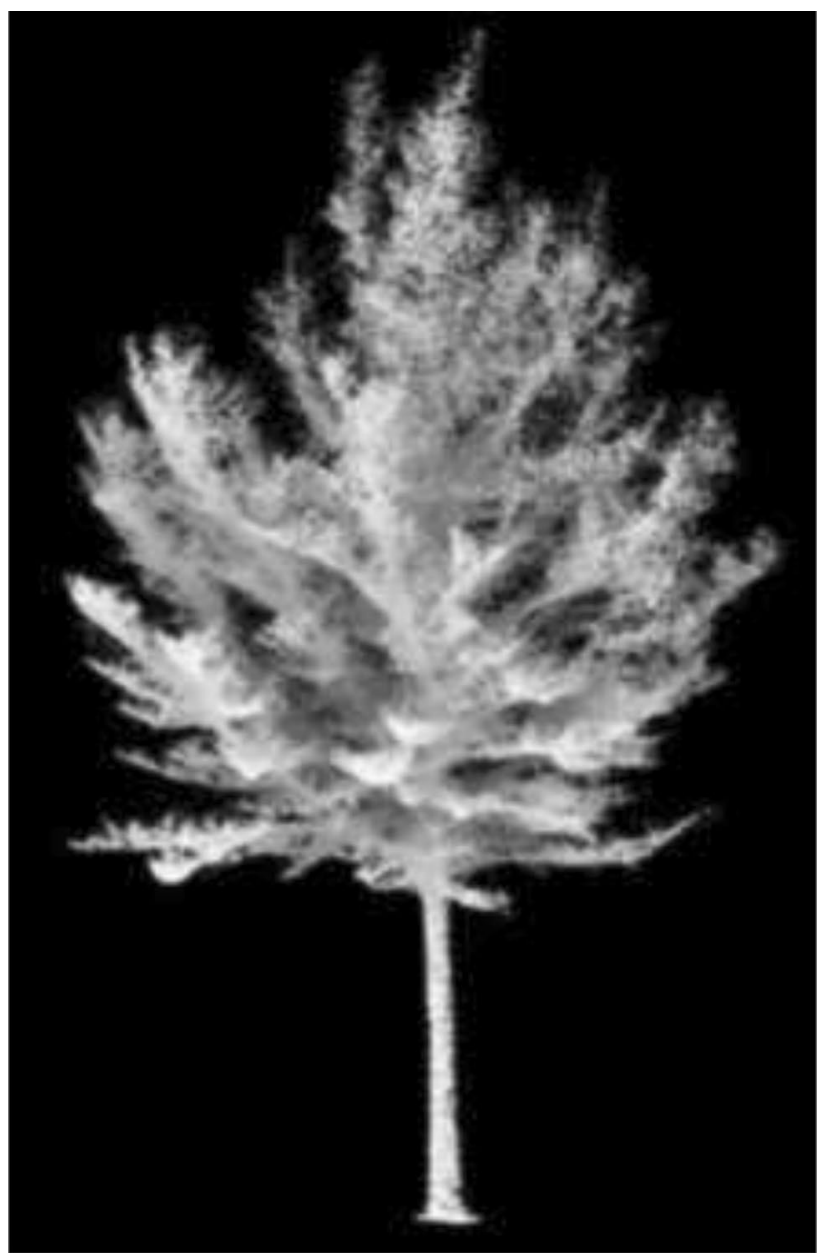

Fig. 3 Exemplary cleaned and filtered 3D point cloud of an Elm tree (Ulmus) obtained from mobile laser scanning

complexity of each tree individual as shown in Seidel (2018). The box dimension can be considered a measure of tree structural complexity (Seidel et al. 2019b). This approach is based on the groundbreaking works of Mandelbrot (1977) and a pioneering study by Sarkar and Chaudhuri (1994). The $D_{\mathrm{b}}$ of each tree was determined by counting the number of virtual boxes of a given size needed to enclose all the above-ground tree parts in the point cloud. We followed the procedure described in Seidel et al. (2019a). In short, we started with an initial box defined by the minimum bounding cube encapsulating the entire tree point cloud and subsequently used smaller boxes by cutting in half the edge length until the lower cutoff of $10 \mathrm{~cm}$ in edge length was reached. The $D_{\mathrm{b}}$ is considered as the slope of the fitted straight line (least square fit) through the scatterplot of the number of boxes in the $y$-axis represented by $\log (N)$ and their size in the $x$-axis represented by $\log (1 / r)$. The log () here is the natural logarithm. ' $N$ ' is the number of boxes of the size ' $r$ ' required to enclose the entire tree's 3D point cloud. In short, the 
slope of the regression line through the log-log-graph is defined as $D_{\mathrm{b}}$ (Mandelbrot 1977).

Conceptually, any 3D object's $D_{\mathrm{b}}$ could range from 1 to 3 , with a cylindrical object having a $D_{\mathrm{b}}$ of one and a cubical object having a $D_{\mathrm{b}}$ of 3 (Seidel et al. 2019b, see also Fig. 4). However, in natural objects and especially in the case of trees, a $D_{\mathrm{b}}$ of three cannot be expected (Mandelbrot 1977). Theoretically, the maximum $D_{\mathrm{b}}$ that could be achieved by the tree is assumed to be 2.72 (Seidel et al. 2019a). However, a $D_{\mathrm{b}}$ of 2.72 would be highly disadvantageous for light utilization due to maximized self-shading of the tree (cf. Seidel et al. 2019a). Therefore, for trees, a $D_{\mathrm{b}}$ between one and some number lower than 2.72 is to be expected (Seidel 2018).

\section{Topological measure of geometry}

We used the relative height of maximum horizontal crown area (Rel.Hmaxarea) to describe the top heaviness of a tree's geometry. It was calculated based on the height of the maximum horizontal crown area in relation to the total tree height. Therefore, it is a relative measure corrected for tree height and given in percent. The underlying parameter "height of maximum crown area" was calculated as described in Seidel et al. (2011). In short, the tree point clouds were split into horizontal layers of $10 \mathrm{~cm}$ in thickness and the area of the convex-hull polygon enclosing all points in each horizontal layer was calculated. The height of the layer with the largest area is considered Hmaxarea [or 'HCPA' (height of maximum crown projection area) in earlier studies]. The relative Hmaxarea was then given in percent of the total tree height. Tree height was derived from the point cloud as the difference between highest point and lowest point in the point cloud of a tree (zmax-zmin).

\section{Results}

Table 1 provides an overview of the studied trees and some general characteristics that were used in our study.

We discovered a significant but weak correlation between the latitudinal mid-point of a species origin and the top heaviness (Rel.Hmaxarea) of the trees (Fig. 5). The most top-heavy tree geometries were found for species originating from Japan and Korea (Prunus serrulata Lindl.) with a latitudinal mid-point of around $38^{\circ} \mathrm{N}$. Individuals of this species had a Rel.Hmaxarea of $76 \%$ on average. Lowest Rel.Hmaxarea of 35\% was identified for individuals of Betula pendula. $\mathrm{R}$ originating from higher latitudes (mid-point $>53^{\circ}$ ).

We also found a significant difference in tree architecture between different seed dispersal strategies. Despite a very similar range of values, trees with wind-dispersed seeds showed, on average, a higher structural complexity $\left(D_{\mathrm{b}}\right)$ than trees with seeds dispersed by animals (Fig. 6).

We also discovered a significant non-linear relationship (represented by the EDF value of 2.58) between the box dimension and the corresponding annual radial increment of the trees (Fig. 7). While trees with a high $D_{\mathrm{b}}$ showed a large variability in growth, trees with a low $D_{\mathrm{b}}$ seem to asymptotically approach a value around $2 \mathrm{~mm}_{\text {year }}{ }^{-1}$ and were hence not able to reach high growth rates. Even though the scatter

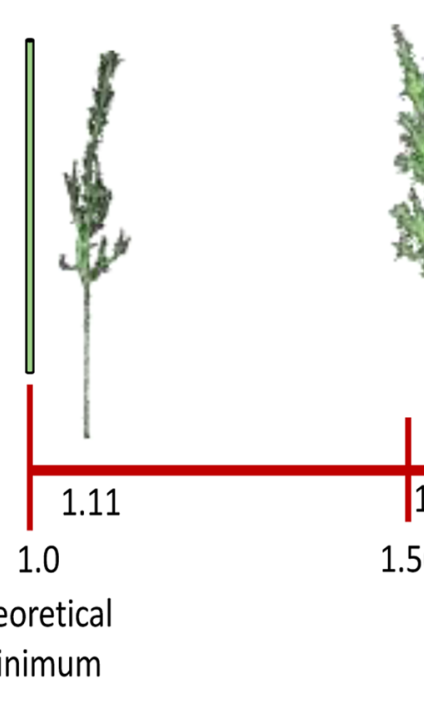

Fig. 4 Example objects for box dimension minimum (box dimension: $1.0=$ pole, topological dimension is also 1) and maximum (box dimension: $3.0=$ cube, topological dimension is also 3). For trees, examples are shown for 1.11 (lowest value observed in our study), $1.54,1.86$, and 2.29 (highest value observed in our study) 
Table 1 Summary of all investigated trees, the number of samples per species/cultivar, mean box dimension $\left(D_{\mathrm{b}}\right)$, mean height, mean latitude of origin, respective seed dispersal strategy, and mean annual radial increment as a measure of growth

\begin{tabular}{|c|c|c|c|c|c|c|}
\hline Species/cultivar & $\begin{array}{l}\text { Number of } \\
\text { trees }\end{array}$ & Mean $D_{\mathrm{b}}$ & $\begin{array}{l}\text { Mean } \\
\text { height (m) }\end{array}$ & Mean latitude $\left({ }^{\circ}\right)$ & Seed dispersal strategy & $\begin{array}{l}\text { Mean annual } \\
\text { radial increment } \\
(\mathrm{cm})\end{array}$ \\
\hline Acer buergerianum & 2 & 2.14 & 6.44 & 36.99 & Wind & 0.27 \\
\hline Acer campestre & 16 & 1.99 & 6.88 & 42.92 & Wind & 0.37 \\
\hline Acer cappadocium & 2 & 1.97 & 6.07 & 40.24 & Wind & 0.32 \\
\hline Acer davidii & 1 & 1.64 & 5.59 & 31.80 & Wind & n.a. \\
\hline Acer freemanii & 4 & 1.95 & 7.64 & 48.67 & Wind & 0.19 \\
\hline Acer griseum & 1 & 2.00 & 4.89 & 46.14 & Wind & 0.22 \\
\hline Acer monspessulanum & 2 & 2.21 & 6.87 & 40.09 & Wind & 0.41 \\
\hline Acer opalus & 4 & 1.94 & 6.00 & 37.32 & Wind & 0.42 \\
\hline Acer platanoides & 18 & 2.01 & 7.10 & 50.47 & Wind & 0.38 \\
\hline Acer pseudoplatanus & 2 & 2.03 & 6.83 & 41.86 & Wind & 0.41 \\
\hline Acer rubrum & 11 & 2.01 & 5.99 & 48.65 & Wind & 0.33 \\
\hline Acer truncatum & 4 & 1.90 & 7.26 & 36.99 & Wind & 0.27 \\
\hline Acer $\times$ neglectum & 2 & 2.13 & 6.92 & n.a. & Not included & 0.44 \\
\hline Aesculus arnoldia & 1 & 1.36 & 4.22 & 48.88 & Animals & n.a. \\
\hline Aesculus glabra & 2 & 1.49 & 4.58 & 48.88 & Not included & n.a. \\
\hline Ailanthusaltissima & 2 & 2.00 & 6.78 & 31.15 & Wind & 0.67 \\
\hline Alnus cordata & 2 & 2.11 & 6.59 & 40.47 & Wind & 0.32 \\
\hline Alnus spaethii & 8 & 2.12 & 7.53 & 51.11 & Not included & 0.35 \\
\hline Amelanchier arborea & 2 & 2.08 & 7.32 & 36.35 & Animals & 0.25 \\
\hline Betula albosinensis & 2 & 2.09 & 7.02 & 36.99 & Not included & 0.13 \\
\hline Betula pendula & 4 & 2.14 & 8.58 & 53.57 & Not included & 0.34 \\
\hline Betula utilis & 4 & 2.11 & 6.67 & 30.91 & Wind & 0.17 \\
\hline Carpinus betulus & 12 & 1.93 & 5.88 & 50.69 & Not included & 0.30 \\
\hline Celtis australis & 2 & 2.07 & 6.75 & 54.23 & Animals & 0.40 \\
\hline Celtis julianae & 4 & 2.08 & 8.29 & 31.00 & Not included & 0.61 \\
\hline Celtis occidentalis & 4 & 2.10 & 7.23 & 43.80 & Animals & 0.43 \\
\hline Cladrastis kentukea & 3 & 2.00 & 5.90 & 40.21 & Animals & 0.43 \\
\hline Corylus colurna & 4 & 2.01 & 6.29 & 36.75 & Animals & 0.26 \\
\hline Crataegus lavallei & 4 & 1.77 & 6.11 & 46.71 & Animals & 0.23 \\
\hline Crataegus persimilis & 4 & 1.82 & 5.99 & 48.88 & Animals & 0.12 \\
\hline Diospyros virginiana & 1 & 1.84 & 4.29 & 48.25 & Animals & n.a. \\
\hline Eucommia ulmoides & 4 & 2.01 & 6.46 & 36.99 & Wind & 0.31 \\
\hline Eиопутия еuropaeus & 2 & 1.77 & 4.19 & 53.57 & Animals & 0.14 \\
\hline Euonymus plainipes & 2 & 1.69 & 3.55 & 50.16 & Animals & 0.09 \\
\hline Fraxinus americana & 4 & 1.77 & 5.61 & 48.88 & Wind & 0.12 \\
\hline Fraxinus angustifolia & 4 & 2.06 & 7.50 & 24.92 & Not included & 0.34 \\
\hline Fraxinus cuspidata & 4 & 1.33 & 5.74 & 29.63 & Wind & n.a. \\
\hline Fraxinus ornus & 20 & 1.88 & 5.99 & 38.28 & Not included & n.a. \\
\hline Fraxinus penn & 4 & 1.56 & 5.46 & 62.95 & Wind & 0.10 \\
\hline Ginkgo biloba & 4 & 1.71 & 5.15 & 45.62 & Not included & n.a. \\
\hline Gleditsia triacanthos & 7 & 2.02 & 6.84 & 36.35 & Animals & n.a. \\
\hline Gymnocladus dioicus & 2 & 1.57 & 5.45 & 48.25 & Not included & 0.15 \\
\hline Koelreuteria paniculata & 1 & 2.04 & 5.37 & 36.99 & Not included & 0.37 \\
\hline Liquidambar styraciflua & 7 & 1.77 & 5.70 & 51.16 & Wind & 0.16 \\
\hline Magnolia denudata & 3 & 1.65 & 5.52 & 30.65 & Animals & n.a. \\
\hline Malus tschonoskii & 3 & 1.82 & 5.74 & 32.98 & Animals & 0.15 \\
\hline Morus alba & 2 & 2.08 & 5.87 & 36.99 & Animals & 0.41 \\
\hline
\end{tabular}


Table 1 (continued)

\begin{tabular}{|c|c|c|c|c|c|c|}
\hline Species/cultivar & $\begin{array}{l}\text { Number of } \\
\text { trees }\end{array}$ & Mean $D_{\mathrm{b}}$ & $\begin{array}{l}\text { Mean } \\
\text { height (m) }\end{array}$ & Mean latitude $\left(^{\circ}\right)$ & Seed dispersal strategy & $\begin{array}{l}\text { Mean annual } \\
\text { radial increment } \\
(\mathrm{cm})\end{array}$ \\
\hline Ostrya japonica & 2 & 1.66 & 5.73 & 32.98 & Wind & 0.10 \\
\hline Ostrya carpinifolia & 8 & 2.05 & 6.04 & 40.09 & Wind & 0.19 \\
\hline Parrotia persica & 3 & 1.62 & 4.38 & 36.05 & Not included & 0.16 \\
\hline Platanus acerifolia & 4 & 2.10 & 4.78 & n.a. & Wind & 0.31 \\
\hline Platanus hispinica & 4 & 1.98 & 7.70 & 52.12 & Wind & 0.31 \\
\hline Platanus orientalis & 8 & 2.03 & 7.82 & 45.30 & Wind & 0.45 \\
\hline Populus trichocarpa & 2 & 1.88 & 6.73 & 50.49 & Wind & n.a \\
\hline Prunus n.a. & 2 & 1.57 & 5.10 & 35.62 & Animals & 0.09 \\
\hline Prunus padus & 3 & 1.99 & 6.38 & 51.06 & Animals & 0.29 \\
\hline Prunus serrulata & 4 & 1.78 & 5.84 & 38.27 & Animals & 0.37 \\
\hline Prunus $\times$ yedonennsis & 2 & 1.96 & 5.38 & 32.98 & Not included & 0.22 \\
\hline Ptelea trifoliata & 3 & 1.90 & 4.38 & 43.26 & Wind & n.a \\
\hline Pyrus calleryana & 8 & 1.93 & 7.55 & 47.05 & Animals & 0.29 \\
\hline Quercus bicolor & 6 & 1.79 & 5.79 & 48.25 & Not included & 0.33 \\
\hline Quercus castaneifolia & 8 & 1.64 & 5.52 & 35.41 & Animals & n.a. \\
\hline Quercus cerris & 8 & 1.87 & 6.98 & 41.92 & Animals & n.a. \\
\hline Quercus ellipsoidalis & 1 & 2.09 & 6.55 & 54.18 & Animals & 0.31 \\
\hline Quercus frainetto & 7 & 1.69 & 5.99 & 46.60 & Not included & n.a \\
\hline Quercus hispanica & 2 & 1.94 & 6.89 & 52.12 & Not included & 0.29 \\
\hline Quercus imbricaria & 2 & 1.83 & 5.03 & 48.25 & Animals & n.a \\
\hline Quercus macrocarpa & 3 & 1.69 & 5.91 & 52.41 & Animals & 0.30 \\
\hline Quercus n.a. & 2 & 1.44 & 4.92 & 48.56 & Not included & n.a \\
\hline Quercus palustris & 2 & 1.37 & 4.88 & 48.88 & Animals & 0.18 \\
\hline Quercus phellos & 2 & 1.80 & 5.28 & 48.25 & Not included & n.a. \\
\hline Quercus pubescens & 5 & 1.94 & 6.07 & 41.23 & Animals & n.a. \\
\hline Quercus rhysophylla & 2 & 1.73 & 5.17 & 26.43 & Animals & n.a \\
\hline Quercus sargentii & 1 & 1.53 & 5.08 & 38.91 & Not included & 0.16 \\
\hline Quercus serrata & 1 & 1.43 & 5.05 & 36.99 & Animals & 0.25 \\
\hline Quercus Shumardii & 4 & 1.74 & 5.51 & 25.53 & Not included & 0.23 \\
\hline Quercus texana & 6 & 1.64 & 5.51 & 32.47 & Animals & n.a. \\
\hline Quercus velutina & 1 & 1.68 & 5.59 & 36.35 & Animals & n.a. \\
\hline Sophora japonica & 6 & 2.19 & 7.41 & 40.74 & Animals & 0.56 \\
\hline Sorbus incana & 2 & 1.86 & 5.53 & 55.68 & Animals & 0.35 \\
\hline Sorbus latifolia & 8 & 1.98 & 6.09 & 51.11 & Animals & 0.31 \\
\hline Sorbus thuringiaca & 6 & 1.90 & 6.02 & n.a. & Animals & 0.26 \\
\hline Sycoparrotia semidecidua & 1 & 1.72 & 3.37 & 36.99 & Not included & n.a. \\
\hline Taxodium distichum & 1 & 2.01 & 6.23 & 26.78 & Not included & 0.18 \\
\hline Tetradium daniellii & 2 & 2.00 & 5.83 & 44.80 & Not included & 0.36 \\
\hline Thuja plicata & 1 & 2.02 & 6.17 & 48.88 & Wind & 0.30 \\
\hline Tilia tomentosa & 1 & 1.52 & 4.93 & 41.69 & Not included & 0.36 \\
\hline Tilia americana & 2 & 2.12 & 6.95 & 48.88 & Not included & 0.35 \\
\hline Tilia cordata & 12 & 2.07 & 6.63 & 52.74 & Not included & n.a. \\
\hline Tilia euchlora & 2 & 1.88 & 6.14 & n.a. & Not included & 0.36 \\
\hline Tilia euchlora $\times$ mongolica & 2 & 1.58 & 5.53 & n.a. & Not included & 0.21 \\
\hline Tilia europaea & 4 & 2.12 & 7.52 & 53.57 & Not included & 0.39 \\
\hline Tilia henryana & 2 & 1.69 & 4.54 & 31.00 & Wind & 0.19 \\
\hline Tilia japonica $\times$ mongolica & 2 & 1.54 & 4.99 & 39.16 & Not included & 0.24 \\
\hline Tilia mandshurica & 2 & 1.56 & 4.27 & 45.24 & Not included & n.a. \\
\hline
\end{tabular}


Table 1 (continued)

\begin{tabular}{|c|c|c|c|c|c|c|}
\hline Species/cultivar & $\begin{array}{l}\text { Number of } \\
\text { trees }\end{array}$ & Mean $D_{\mathrm{b}}$ & $\begin{array}{l}\text { Mean } \\
\text { height (m) }\end{array}$ & Mean latitude $\left({ }^{\circ}\right)$ & Seed dispersal strategy & $\begin{array}{l}\text { Mean annual } \\
\text { radial increment } \\
(\mathrm{cm})\end{array}$ \\
\hline Tilia mongolica & 6 & 1.94 & 5.20 & 43.99 & Wind & n.a. \\
\hline Tilia monticola & 2 & 1.24 & 5.31 & 48.88 & Not included & 0.19 \\
\hline Tilia platyphyllos & 8 & 2.05 & 7.33 & 47.84 & Not included & 0.37 \\
\hline Tilia tomentosa & 20 & 2.06 & 6.51 & 48.23 & Animals & n.a. \\
\hline Tilia $\times$ moltkei & 1 & 1.54 & 4.90 & n.a. & Not included & 0.25 \\
\hline Ulmus laevis & 2 & 2.00 & 8.35 & 57.76 & Wind & 0.62 \\
\hline Ulmus spp. & 47 & 1.99 & 7.84 & 52.74 & Wind & n.a. \\
\hline Viburnum lentago & 2 & 1.94 & 3.92 & 43.80 & Animals & 0.07 \\
\hline Zelkovaserrata & 6 & 2.02 & 6.37 & 32.98 & Wind & 0.33 \\
\hline Total & 473 & & & & & \\
\hline
\end{tabular}

n.a. missing data, Not included species' seed dispersal strategy was not relying on a single mechanism or the mechanism could not be identified

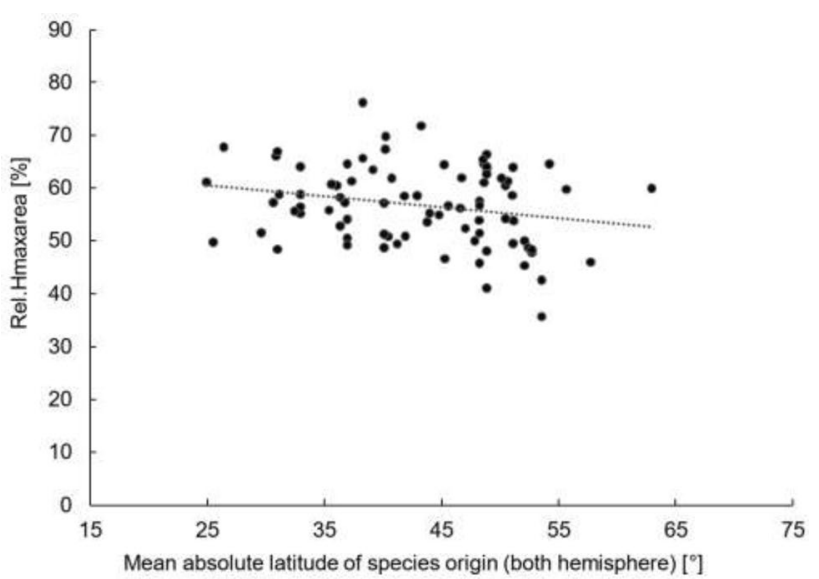

Fig. 5 Scatterplot of relative height of maximum horizontal crown area (Rel.Hmaxarea) over mean absolute latitude (latitudinal midpoint) of each species origin. The coefficient of determination $\left(R^{2}\right)$ was 0.052 but significant with $p<0.05 ; n=83$ species (mean values per species)

of the data is high, the GAM model explained more than $35 \%$ of the deviance.

\section{Discussion}

We hypothesized that trees growing in the Stutel-Arboretum originating from different latitudes would show crown shapes indicating adaptations to the solar elevation angles at the latitude of their species' home range. Our results derived from 3D point cloud data obtained through MLS support this hypothesis (See Fig. 5). Trees from species of different origins tended to have a more top-heavy geometry when the latitude of their species origin was lower, despite the fact that the individuals investigated here were growing at the same geographical and environmental settings. Even though

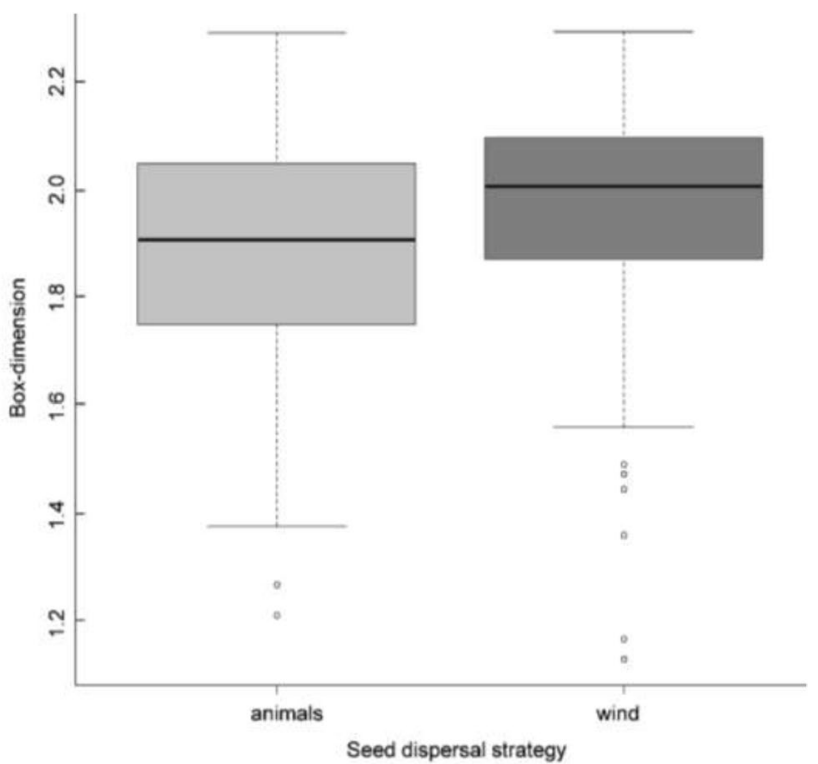

Fig. 6 Box-and-Whisker plot of trees of different seed dispersal strategies, namely, wind $(n=192)$ and animal $(n=130)$ dispersed. The difference in means was significant at $p<0.001$ (animal-dispersed mean: 1.87; wind-dispersed mean: 1.95 )

the relationship was weak $\left(R^{2}=0.052\right)$, it was significant, indicating the existence of a genetic determination. Trees originating from high latitudes with prevailing low solar elevation angles developed deeper crowns with lower Rel. Hmaxarea to efficiently intercept light when compared to trees of lower latitudes exposed to higher solar elevation angles. The latter develop more top-heavy crowns resulting in a higher Rel.Hmaxarea. This empirical data support the previous studies which suggested that there should be a measurable role of the solar incident angle on the shape of trees (Hallé et al. 1978; Whitmore 1975; Terborgh 1985; Hiura 1998; King 2005; Tateishi et al. 2010; Bomfleur et al. 


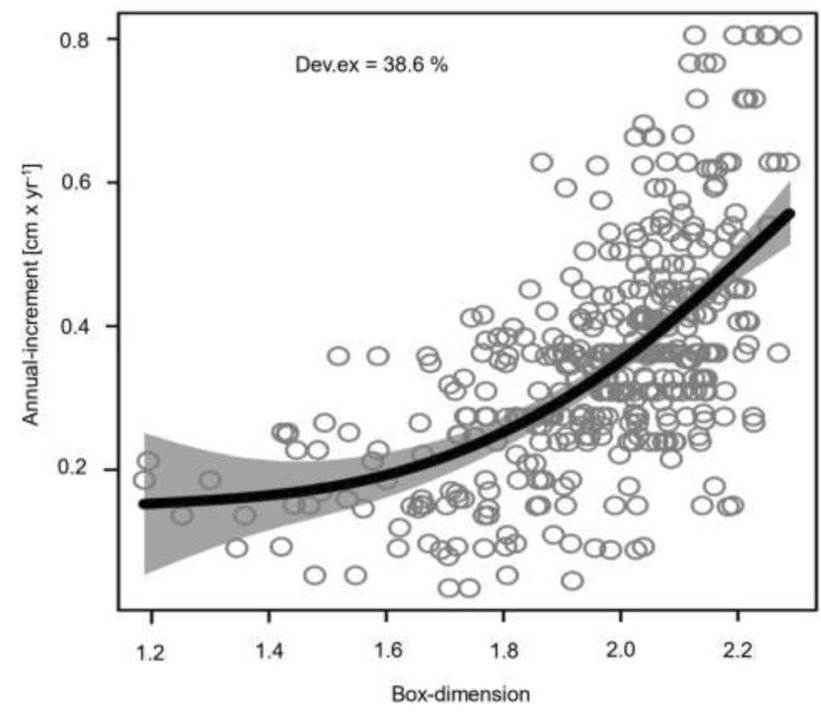

Fig. 7 Scatterplot of annual radial increment as a measure of growth over the box dimension and GAM regression. The relationship is significant at $p<0.001$; adjusted $R^{2}=0.364$; effective degrees of freedom $(E D F)=2.58$. Growth data were available for $n=391$ tree individuals. Dev.ex. deviation explained

2013). However, on our experimental site, with comparable growing conditions for all study trees, we found only a small strength of the effect of crown shape adaption to the latitude of origin. It is important to consider that the mid-point latitude of a species' origin could only be estimated, since exact information of the natural distribution of the species is often unavailable. This may partly explain the rather lower explanatory power of latitude for Rel.Hmaxarea (Fig. 5). Furthermore, we argue that the relationship is not very strong, because tree architecture is not just determined by the solar angle. According to the optimized resource utilization strategy, the trees need to balance various biotic and abiotic factors to result in an optimized tree shape (Archibald and Bond 2003; Minamino and Tateno 2014). Therefore, during the last years, the trees also responded plastically to the conditions at the study site, strongly reducing the observable "legacy" in geometry.

According to the literature, there is reason to expect a relationship between the solar geometry at a particular latitude and the shape of the trees that grow there (Kuuluvainen 1992). Our approach of analyzing this relationship was limited to measuring a genetic legacy effect of solar geometry by relating a tree's shape to the latitude of the tree species natural distribution. We suspect that the reason for the small effect size of the relationship described in Fig. 5 is that the capability of a tree to adapt its shape to prevailing biotic and abiotic factors may strongly outweigh the genetic predisposition of a tree to grow a particular shape. However, if we want to gain a better understanding of exactly how strong the influence of solar geometry on tree morphology is, it is necessary to directly relate a tree's latitude (or solar zenith angle at that latitude) to the shape of the tree. This would require extensive point cloud data of many trees from a wide range of latitudes. Pooling together, a large number of georeferenced tree point clouds would enable the establishment of a more direct relationship between solar geometry and tree morphology, moving beyond the limitation of only being able to look at genetic legacy effects. Future research in this field should focus on international collaborations and data sharing for that matter.

Since many crucial factors were the same for all our trees (e.g., water availability, temperature, nutrient availability, and competition), we were able to investigate the relationship between tree architectural complexity $\left(D_{\mathrm{b}}\right)$ and seed dispersal strategy. $D_{\mathrm{b}}$ is a measure of tree architecture that integrates many other conventional topological measures, like tree height, crown volume, crown radius, branch angle variability, and others (Seidel et al. 2019a, c). Hence, we hypothesized that $D_{\mathrm{b}}$ should be related to a species' seed dispersal strategy since seed dispersal, and accordingly reproduction, are a key functional role of tree architecture (Malhi et al. 2018). Indeed, we found that mean structural complexity, as summarized by the $D_{\mathrm{b}}$ values, differed significantly between trees species with wind-dispersed seeds and animaldispersed seeds. Hence, our second hypothesis is supported by our results (Fig. 6). Malhi et al. (2018) proposed that there are differences in the tree architecture, for example between Southeast Asian forests, in which species predominantly rely on wind dispersal and trees of the forest in central Africa and central Amazonia that are predominantly animaldispersed. Our data indicate that anemochorus tree species are more structurally complex in shape than zoochorus tree species. We hypothesize that less-complex tree crowns provide easier access and visual attraction for animals, while highly complex tree crowns with many branches and greater overall surface, as indicated by the high $D_{\mathrm{b}}$ value, may be a greater barrier to wind and hence increase wind speeds wherever wind funnels through the crown. Final conclusions on this matter require more research, since our study trees were of rather young age.

Our third hypothesis was that a higher $D_{\mathrm{b}}$ is related to higher radial increment, and it was supported by our results (Fig. 7). Earlier studies already identified this relationship for some selected tree species including some temperate and tropical species (Seidel 2018; Seidel et al. 2019b). While previous studies observed linear relationships, the observed relationship in our current study appeared to be non-linear according to the GAM model with more than $35 \%$ explained deviation. In fact, when modelled linearly, the deviance explained is still $32 \%$ in our data. So far, the functional explanation of the relationship between the box dimension and tree growth has been that an increased $D_{\mathrm{b}}$ is often a result of reduced competition (e.g., Dorji et al. 2019) 
that led to unrestricted growth and hence better growth performance. Additionally, it was shown that a greater $D_{\mathrm{b}}$ was directly linked to a more efficient ratio of the photosynthetic surface area to wooden tree volume, or in other words, a better ratio between "producing" and "consuming" organs (Seidel et al. 2019b). We hypothesize that a greater positive effect on productivity at higher rates of complexity than at lower rates of complexity may be explained by the fractal nature of the tree crown, with increased levels of branching (higher branch order being build), resulting in disproportional benefit to the tree. Since additional higher-order twigs are present in trees with greater complexity, there may often be smaller 'investments' (in terms of wooden structures) needed to produce additional light-capturing tissue surface in those canopies, when compared to rather polelike tree crowns, where additional branches must first reach the light-exposed outer area of the crown (=larger investment) before light-capturing tissue can be exposed to sunlight. While this remains a hypothesis until further research addresses the issue, we could show that there seems to be a general positive relationship between structural complexity and productivity. Particularly for temperate climates, a large $D_{\mathrm{b}}$ is related to a more efficient tree architecture (cf. Seidel et al. 2019a). However, if genetically disposed towards more domed, umbrella-like crowns, as required for efficient growth in the subtropics, trees can only adapt to a certain extent towards the conditions in the arboretum and hence carry the legacy of their original habitat. Together with potential other effects (adaptation to soil, climate, genetic predisposition, etc.), this results in lower growth rates compared to well-adapted tree species with optimized crown shapes. In subtropical or tropical climates, a high $D_{\mathrm{b}}$ would only be beneficial to trees that either grow in the understory (capturing indirect light), like those investigated in Seidel et al. (2019a), or trees that are predominantly facing overcast conditions with large amount of indirect light. High solar angles in the tropics and subtropics would otherwise result in intense self-shading, resulting in a questionable benefit from a large, multilayered, and complex tree crown as indicated by a high $D_{\mathrm{b}}$.

In all the above findings, the use of 3D data in combination with topological and particularly fractal geometry proved to be vital in translating the tree architectural complexity into numbers that enable relating it to functional traits. In earlier times, characterizing the tree architecture mathematically was hardly possible due to the unavailability of 3D data (Borchert and Slade 1981), which severely limited our advancement in understanding of drivers and passengers of tree structural complexity. As outlined by recent studies, laser scanning provides a new and unprecedented way of looking at the relationship between tree structure and functions (Malhi et al. 2018; Calders et al. 2020). Thus, it may be the perfect method for further developing functional-structural plant models that are needed to better explain the growth performance of mixed stands (Bongers 2020).

\section{Conclusions}

Here, we used ground-based mobile laser scanning to scan 473 trees and generate three-dimensional data of each tree. We used fractal analysis and a topological measure of geometry to characterize the tree architectural complexity and geometry. We detected a positive relationship between tree structural complexity and tree growth, as well as a difference in the tree architectural complexity based on different seed dispersal strategies. Furthermore, we detected an effect of the latitude of a species' origin on the geometry of trees growing at our study site. Tree species from lower latitudes were more top-heavy in shape than tree species originating from higher latitudes. We argue that 3D data from mobile laser scanning, particularly in combination with novel tools to assess geometry, like the box-dimension approach, are an efficient and holistic means to characterize tree architecture. Simplifying structural complexity and geometrical characteristics into single numbers can be applied to trees or entire forest stands, providing a means for quantifying complexity and relating it to a diverse functional pattern of trees and forests. This enables new insights into the relationship between the structure and function of terrestrial ecosystems.

Author contribution statement YD, BS, CA, and DS developed the concept of the study. YD, LN, RD, KM, EI, KK, and DS collected the data. YD, PA, and DS analyzed the data. YD and DS wrote the manuscript and BS, RD, LN, EI, KK, KM, CA, and PA performed critical revision. All authors gave the final approval.

Acknowledgements We are grateful to the anonymous reviewers for their valuable comments. We thank the Bavarian State Institute for Viticulture and Horticulture, Veitshochheim, Germany, for granting us access to the Stutel-Arboretum facility, as well as Andreas Lösch and all others involved in the 'Klimabaüme Stutel' Project (http://www.lwg. bayern.de/gartenbau/baumschule/101342/index.php/).

Funding Open Access funding enabled and organized by Projekt DEAL. This research was funded through DFG grant SE2383/5-1 provided to Dominik Seidel and was further supported by funds of the German government's Special Purpose Fund held at Landwirtschaftliche Rentenbank (FKZ: 844732) provided to Dominik Seidel.

Data availability The data are available at Dryad under the https://doi. org/10.5061/dryad.2fqz612n6. 
Code availability The code will be made available upon request (please contact the corresponding author).

\section{Declaration}

Conflict of interest The authors declare no conflict of interest.

Open Access This article is licensed under a Creative Commons Attribution 4.0 International License, which permits use, sharing, adaptation, distribution and reproduction in any medium or format, as long as you give appropriate credit to the original author(s) and the source, provide a link to the Creative Commons licence, and indicate if changes were made. The images or other third party material in this article are included in the article's Creative Commons licence, unless indicated otherwise in a credit line to the material. If material is not included in the article's Creative Commons licence and your intended use is not permitted by statutory regulation or exceeds the permitted use, you will need to obtain permission directly from the copyright holder. To view a copy of this licence, visit http://creativecommons.org/licenses/by/4.0/.

\section{References}

Archibald S, Bond WJ (2003) Growing tall vs growing wide: tree architecture and allometry of Acacia karroo in forest, savanna, and arid environments. Oikos 102(1):3-14. https://doi.org/10.1034/j. 1600-0706.2003.12181.x

Barij N, Stokes A, Bogaard T, Beek RV (2007) Does growing on a slope affect tree xylem structure and water relations? Tree Physiol 27(5):757-764. https://doi.org/10.1093/treephys/27.5.757

Bayer D, Seifert S, Pretzsch H (2013) Structural crown properties of Norway spruce (Picea abies [L.] Karst.) and European beech (Fagus sylvatica [L.]) in mixed versus pure stands revealed by terrestrial laser scanning. Trees 27(4):1035-1047. https://doi.org/ 10.1007/s00468-013-0854-4

Beech E, Rivers M, Oldfield S, Smith PP (2017) GlobalTreeSearch: the first complete global database of tree species and country distributions. J Sustain For 36(5):454-489. https://doi.org/10.1080/ 10549811.2017.1310049

Bentley LP, Stegen JC, Savage VM, Smith DD, von Allmen EI, Sperry JS, Reich PB, Enquist BJ (2013) An empirical assessment of tree branching networks and implications for plant allometric scaling models. Ecol Lett 16:1069-1078. https://doi.org/10.1080/10549 811.2017.1310049

Bomfleur B, Decombeix AL, Escapa IH, Schwendemann AB, Axsmith B (2013) Whole-plant concept and environment reconstruction of a telemachus conifer (Voltziales) from the Triassic of Antarctica. Int J Plant Sci 174:425-444. https://doi.org/10.1086/668686

Bongers FJ (2020) Functional-structural plant models to boost understanding of complementarity in light capture and use in mixedspecies forests. Basic Appl Ecol 48:92-101. https://doi.org/10. 1016/j.baae.2020.09.007

Borchert R, Slade NA (1981) Bifurcation ratios and the adaptive geometry of trees. Bot Gaz 142(3):394-401. https://doi.org/10.1086/ 337238

Bradshaw HD, Stettler RF (1995) Molecular genetics of growth and development in populus. IV. Mapping QTLs with large effects on growth, form, and phenology traits in a forest tree. Genetics 139(2):963-973

Burkardt K, Pettenkofer T, Ammer C, Gailing O, Leinemann L, Seidel D, Vor T (2020) Influence of heterozygosity and competition on morphological tree characteristics of Quercus rubra L.: a new single-tree based approach. New For. https://doi.org/10.1007/ s11056-020-09814-1
Busov VB, Brunner AM, Strauss SH (2008) Genes for control of plant stature and form. New Phytol 177(3):589-607. https://doi.org/10. 1111/j.1469-8137.2007.02324.x2007.02324.x

Calders K, Phinn S, Ferrari R, Leon J, Armston J, Asner GP, Disney M (2020) 3D imaging insights into forests and coral reefs. Trends Ecol Evol 35(1):6-9. https://doi.org/10.1016/j.tree.2019.10.004

Clark JS, Silman M, Kern R, Macklin E, HilleRisLambers J (1999) Seed dispersal near and far: patterns across temperate and tropical forests. Ecology 80:1475-1494. https://doi.org/10.2307/176541

Darwin CR (1859) The origin of species. John Murray, London

Disney M (2019) Terrestrial LiDAR: a three-dimensional revolution in how we look at trees. New Phytol 222:1736-1741. https://doi. org/10.1111/nph.15517

Dorji Y, Annighöfer P, Ammer C, Seidel D (2019) Response of beech (Fagus sylvatica L.) trees to competition-new insights from using fractal analysis. Remote Sens 11(22):2656. https://doi.org/ $10.3390 /$ rs 11222656

De Langre E (2008) Effects of wind on plants. Annu Rev Fluid Mech 40:141-168. https://doi.org/10.1146/annurev.fluid.40.111406. 102135

Enquist JB, West BG, Brown HJ (2009) Extensions and evaluations of a general quantitative theory of forest structure and dynamics. Proc Natl Acad Sci USA 106(17):7040-7051. https://doi.org/10. 1073/pnas.0812303106

EUFORGEN (1994) European forest genetic resources program. http:// www.euforgen.org/species/. Accessed 15 June 2020

Forrester DI, Ammer C, Annighöfer PJ, Barbeito I, Bielak K, BravoOviedo A et al (2018) Effects of crown architecture and stand structure on light absorption in mixed and monospecific Fagus sylvatica and Pinus sylvestris forests along a productivity and climate gradient through Europe. J Ecol 106(2):746-760. https://doi. org/10.1111/1365-2745.12803

GeoSLAM (2019) ZEB-HORIZON User's Manual v1.2 GeoSLAM. https://geoslam.com/solutions/zeb-horizon/. Accessed 19 June 2020

Gering LR, May DM (1995) The relationship of diameter at breast height and crown diameter for four species groups in Hardin County, Tennessee. South J Appl For 19(4):177-181. https://doi. org/10.1093/sjaf/19.4.177

Gonzalez de Tanago J, Lau A, Bartholomeus H, Herold M, Avitabile V, Raumonen P, Martius C, Goodman RC, Disney M, Manuri S, Burt A (2018) Estimation of above-ground biomass of large tropical trees with terrestrial LiDAR. Methods Ecol Evol 9(2):223-234. https://doi.org/10.1111/2041-210X.12904

Google E (2013) Version: Google earth pro (7.1.2.2041). https://www. google.com/earth/versions/. Accessed 19 June 2020

Guisasola R, Tang X, Bauhus J, Forrester DI (2015) Intra- and interspecific differences in crown architecture in Chinese subtropical mixed-species forests. For Ecol Manag 353:164-172. https://doi. org/10.1016/j.foreco.2015.05.029

Guzmán QJA, Sharp I, Alencastro F, Sánchez-Azofeifa GA (2020) On the relationship of fractal geometry and tree-stand metrics on point clouds derived from terrestrial laser scanning. Methods Ecol Evol 11(10):1309-1318. https://doi.org/10.1111/2041-210X. 13437

Hallé F, Oldeman RAA (1970) Essai sur l'architecture et la dynamique de croissance des arbres tropicaux. Paris, France

Hallé F, Oldeman RAA, Tomlinson PB (1978) Tropical trees and forest: an architectural analysis. Springer, New York

Hamrick JL, Murawski DA, Nason JD (1993) The influence of seed dispersal mechanisms on the genetic structure of tropical tree populations. Vegetatio 107(1):281-297. https://doi.org/10.1007/ BF00052230

Hasting HM, Sugihara G (1993) Fractals: a user's guide for the natural sciences. Oxford University Press, Oxford 
Hiura T (1998) Shoot dynamics and architecture of saplings in Fagus crenata across its geographical range. Trees 12:274-280. https:// doi.org/10.1007/PL00009717

Hollender CA, Dardick C (2015) Molecular basis of angiosperm tree architecture. New Phytol 206:541-556. https://doi.org/10.1111/ nph. 13204

Honda H, Fisher JB (1978) Tree branch angle: maximizing effective leaf area. Science 199(4331):888-890. https://doi.org/10.1126/ science.199.4331.888

Horn HS (1971) The adaptive geometry of trees. Princeton University Press, Princeton

Howe HF, Smallwood J (1982) Ecology of seed dispersal. Annu Rev Ecol Syst 13:201-228. https://doi.org/10.1146/annurev.es.13. 110182.001221

Iwasa YO, Cohen DA, Leon JA (1985) Tree height and crown shape, as results of competitive games. J Theor Biol 112(2):279-297. https://doi.org/10.1016/S0022-5193(85)80288-5

Juchheim J, Annighöfer P, Ammer C, Calders K, Raumonen P, Seidel D (2017) How management intensity and neighborhood composition affect the structure of beech (Fagus sylvatica $\mathrm{L}$.) trees. Trees 31(5):1723-1735. https://doi.org/10.1007/s00468-017-1581-z

Kenis K, Keulemans J (2007) Study of tree architecture of apple (Malus $\times$ domestica Borkh.) by QTL analysis of growth traits. Mol Breed 19(3):193-208. https://doi.org/10.1007/s11032-006-9022-5

King DA (2005) Architectural differences in saplings of temperate versus tropical angiosperms; consequences of the deciduous habit? Can J Bot 83:1391-1401. https://doi.org/10.1139/b05-109

Kuuluvainen T (1992) Tree architectures adapted to efficient light utilization: Is there a basis for latitudinal gradients? Oikos 656(2):275-284. https://doi.org/10.2307/3545019

Li Y, Su Y, Hu T, Xu G, Guo Q (2018) Retrieving 2-D leaf angle distributions for deciduous trees from terrestrial laser scanner data. IEEE Trans Geosci Remote 56(8):4945-4955. https://doi.org/10. 1109/TGRS.2018.2843382

Lindh M, Falster DS, Zhang L, Dieckmann U, Brännström ^ (2018) Latitudinal effects on crown shape evolution. Ecol Evol 8(16):8149-8158. https://doi.org/10.1002/ece3.4275

Loewer P (2005) Seeds: the definitive guide to growing, history and lore. Timber Press, Portland

Losa GA (2012) Fractals and their contribution to biology and medicine. Medicographia 34(3):364-374

Malhi Y, Jackson T, Patrick Bentley L, Lau A, Shenkin A, Herold M, Calders K, Bartholomeus H, Disney MI (2018) New perspectives on the ecology of tree structure and tree communities through terrestrial laser scanning. Interface Focus 8(2):20170052. https:// doi.org/10.1098/rsfs.2017.0052

Mandelbrot BB (1977) The fractal geometry of nature. W.H. Freeman Company, New York

Martin-Garin B, Lathuilière B, Verrecchia EP, Geister J (2007) Use of fractal dimensions to quantify coral shape. Coral Reefs 26(3):541550. https://doi.org/10.1007/s00338-007-0256-4

Metz J, Seidel D, Schall P, Scheffer D, Schulze ED, Ammer C (2013) Crown modeling by terrestrial laser scanning as an approach to assess the effect of aboveground intra- and interspecific competition on tree growth. For Ecol Manag 310:275-288. https://doi.org/ 10.1016/j.foreco.2013.08.014

Minamino R, Tateno M (2014) Tree branching: Leonardo da Vinci's rule versus biomechanical models. PLoS One 9(4):e93535. https:// doi.org/10.1371/journal.pone.0093535

Moorthy I, Miller JR, Berni JA, Zarco-Tejada P, Hu B, Chen J (2011) Field characterization of olive (Olea europaea L.) tree crown architecture using terrestrial laser scanning data. Agric For Meteorol 151(2):204-214. https://doi.org/10.1016/j.agrformet.2010. 10.005

Niinemets Ü, Kull O (1995) Effects of light availability and tree size on the architecture of assimilative surface in the canopy of Picea abies: variation in needle morphology. Tree Physiol 15(5):307315. https://doi.org/10.1093/treephys/15.5.307

Niklas KJ (1986) Computer simulations of branching patterns and their implications on the evolution of plants. Lect Math Life Sci 18:1-50

Noguchi Y (1979) Deformation of trees in Hawaii and its relation to wind. J Ecol 67:611-628. https://doi.org/10.2307/2259116

Oker-Blom P, Kellomaki S (1982) Theoretical computations on the role of crown shape in the absorption of light by forest trees. Math Biosci 59:291-311. https://doi.org/10.1016/0025-5564(82) 90028-1

Oyama H, Fuse O, Tomimatsu H, Seiwa K (2018) Ecological properties of shoot- and single seeds in a hardwood, Zelkova serrata. Data Brief 18:1734-1739. https://doi.org/10.1016/j.dib.2018.04. 101

Price CA, Weitz JS, Savage VM, Stegen J, Clarke A, Coomes DA, Dodds PS, Etienne RS, Kerkhoff AJ, McCulloh K, Niklas KJ (2012) Testing the metabolic theory of ecology. Ecol Lett 15(12):1465-1474. https://doi.org/10.1111/j.1461-0248.2012. 01860.x

R Core Team (2018) R: A language and environment for statistical computing. R Foundation for Statistical Computing, Vienna

Richter JP (1970) The notebooks of Leonardo da Vinci. Dover, New York

Sarkar N, Chaudhuri BB (1994) An efficient differential box-counting approach to compute fractal dimension of image. IEEE Trans Syst Man Cybern 24(1):115-120

Schmidt W (1918) Die Verbreitung von Samen und Blütenstaub durch die Luftbewegung. Oesterr Bot Z 67:313-328

Scorza R, Bassi D, Liverani A (2002) Genetic interactions of pillar (columnar), compact, and dwarf peach tree genotypes. J Am Soc Hortic Sci 127(2):254-261. https://doi.org/10.21273/JASHS. 127.2.254

Scotti-Saintagne C, Bodénes C, Barreneche T, Bertocchi E, Plomion C, Kremer A (2004) Detection of quantitative trait loci controlling bud burst and height growth in Quercus robur L. Theor Appl Genet 109(8):1648e1659. https://doi.org/10.1007/ s00122-004-1789-3

Segura V, Cilas C, Laurens F, Costes E (2006) Phenotyping progenies for complex architectural traits: a strategy for 1-year-old apple trees (Malus x domestica Borkh.). Tree Genet Genomes 2(3):140 151. https://doi.org/10.1007/s11295-006-0037-1

Seidel D (2018) A holistic approach to determine tree structural complexity based on laser scanning data and fractal analysis. Ecol Evol 8(1):128-134. https://doi.org/10.1002/ece3.3661

Seidel D, Leuschner C, Müller A, Krause B (2011) Crown plasticity in mixed forests: quantifying asymmetry as a measure of competition using terrestrial laser scanning. For Ecol Manag 261(11):21232132. https://doi.org/10.1016/j.foreco.2011.03.008

Seidel D, Schall P, Gille M, Ammer C (2015) Relationship between tree growth and physical dimensions of Fagus sylvatica crowns assessed from terrestrial laser scanning. IForest 8:735-742. https://doi.org/10.3832/ifor1566-008

Seidel D, Annighöfer P, Stiers M, Zemp CD, Burkardt K, Ehbrecht M, Willim K, Kreft H, Hölscher D, Ammer C (2019a) How a measure of tree structural complexity relates to architectural benefitto-cost ratio, light availability, and growth of trees. Ecol Evol 9(12):7134-7142. https://doi.org/10.1002/ece3.5281

Seidel D, Ehbrecht M, Annighöfer P, Ammer C (2019b) From tree to stand-level structural complexity: which properties make a forest stand complex? Agric Forest Meteorol 278:107699. https://doi. org/10.1016/j.agrformet.2019.107699

Seidel D, Ehbrecht M, Dorji Y, Jambay J, Ammer C, Annighöfer P (2019c) Identifying architectural characteristics that determine tree structural complexity. Trees 33(3):911-919. https://doi.org/ 10.1007/s00468-019-01827-4 
SID (2020) Royal Botanic Gardens Kew Seed Information Database. Version 7.1. http://data.kew.org/sid/. Accessed 15 July 2020

Sprinz PT, Burkhart HE (1987) Relationships between tree crown, stem, and stand characteristics in unthinned loblolly pine plantations. Can J For Res 17(6):534-538. https://doi.org/10.1139/ x87-089

Sterck FJ, Bongers F (2001) Crown development in tropical rain forest trees: patterns with tree height and light availability. J Ecol 89(1):1-13. https://doi.org/10.1046/j.1365-2745.2001.00525.x

Su Y, Hu T, Wang Y, Li Y, Dai J, Liu H, Jin S, Ma Q, Wu J, Liu L, Fang J (2020) Large-scale geographical variations and climatic controls on crown architecture traits. J Geophys Res Biogeosci 125(2):e2019JG005306. https://doi.org/10.1029/2019JG005306

Tao S, Wu F, Guo Q, Wang Y, Li W, Xue B et al (2015) Segmenting tree crowns from terrestrial and mobile LiDAR data by exploring ecological theories. Remote Sens ISPRS J Photogramm Remote Sens 110:66-76. https://doi.org/10.1016/j.isprsjprs.2015.10.007

Tateishi M, Kumagai T, Suyama Y, Hiura T (2010) Differences in transpiration characteristics of Japanese beech trees, Fagus crenata, in Japan. Tree Physiol 30(6):748-760. https://doi.org/10. 1093/treephys/tpq023

Terborgh J (1985) The vertical component of plant species diversity in temperate and tropical forests. Am Nat 126(6):760-776

Tiebel K, Leinemann L, Hosius B, Schlicht R, Frischbier N, Wagner S (2019) Seed dispersal capacity of Salix caprea L. assessed by seed trapping and parentage analysis. Eur J For Res 138(3):495-511. https://doi.org/10.1007/s10342-019-01186-2

Valladares F, Niinemets U (2007) The architecture of plant crowns: from design rules to light capture and performance. Funct Plant Ecol. https://doi.org/10.1201/9781420007626

Vdberk (2020) Van der Berk Nurseries. 1600 species of trees and shrubs https://www.vdberk.com/trees/. Accessed 16 June 2020
Wagner S, Wälder K, Ribbens E, Zeibig A (2004) Directionality in fruit dispersal models for anemochorous forest trees. Ecol Model 179(4):487-498. https://doi.org/10.1016/j.ecolmodel. 2004.02.020

Watt MS, Moore JR, McKinlay B (2005) The influence of wind on branch characteristics of Pinus radiata. Trees 19(1):58-65. https:// doi.org/10.1007/s00468-004-0363-6

West BG, Enquist JB, Brown HJ (2009) A general quantitative theory of forest structure and dynamics. Proc Natl Acad Sci USA 106:7040-7045. https://doi.org/10.1073/pnas.0812294106

Whitmore TC (1975) The tropical rain forests of the Far East. Clarendon Press, Oxford

Wood SN (2017) Generalized additive models: an introduction with R, 2nd edn. Taylor Francis, New York, p 476. https://doi.org/10. 1201/9781315370279

Wu R, Stettler RF (1998) Quantitative genetics of growth and development in Populus. III. Phenotypic plasticity of crown structure and function. Heredity 81(3):299-310. https://doi.org/10.1046/j. 1365-2540.1998.00397.x

Xu Y, Iida H, Shi Z, Franklin SB, Luo Y, Bao D, Qiao X, Lu Z, Jiang M (2019) Linkages between tree architectural designs and lifehistory strategies in a subtropical montane moist forest. For Ecol Manag 438:1-9. https://doi.org/10.1016/j.foreco.2019.01.047

Publisher's note Springer Nature remains neutral with regard to jurisdictional claims in published maps and institutional affiliations. 